\title{
Development of the judgments of kindness in children
}

\author{
KATSUMII NINOMIYA ${ }^{1}$ \\ College of General Education, Aichigakuin University, Nisshin-cho, Aichi 470-01
}

\begin{abstract}
The purpose of this study was to investigate the developmental sequence in children's judgments of kindness in a situation of intentionality. The Kindness Judgment Interview was conducted by using three different story types in which parameters on intentions and consequences (benefits) were varied. Sixty-three subjects consisting of kindergarteners, first and third graders were individually interviewed to assess their judgments of kindness. There were no sex differences in judgments, but significant age differences occurred. Judgments of kind acts on the basis of intention were scalable suggesting a 4-stage developmental sequence: (1) intentions irrelevant, (2) intentions relevant but benefits more important, (3) intentions more important than benefits but benefits still relevant, and (4) intentions alone relevant. These findings were consistent with those of Gutkin's study (1972) in children's naughtiness judgments.
\end{abstract}

Key words: judgments of kindness, intentionality, moral judgments, developmental sequences, children.

What acts do we recognize as being kind among various acts which people display in everyday life? Baldwin and Baldwin (1970) studied this problem of recognition of kind acts. They defined kindness as a motivation that is sometimes inferred from the fact that one person benefits another, provided the circumstances are appropriate. They examined development of children's concepts of kindness based on the assumption of naive psychology (Heider, 1958) that says only intentional acts are judged to reflect some characteristics of the actor.

In their study, each subject was presented to a pair of stories in which an unintentional and an intentional benefit were contrasted. The subjects were asked to select a picture in which they thought the child was kinder, and to explain why they made the choice. Although, in each pair of stories the actual benefit was made the same, the results showed that the intentional acts were judged as kinder than the

1 The author would like to express appreciation to Professors Toshio Kuze and Mitsuru Wakabayashi for their assistances in preparing this article. unintentional ones with increase in age.

Gutkin (1972) constructed the six different possible story-pair combinations (story types) in which a systematic variation was made on the values (good-bad, high-low) of the two salient variables, intentions and consequences (damage). Gutkin found the six different story types elicited different numbers of subjective judgments on the basis of intentions. $\mathrm{He}$ also found that story pairs of type A (goodintention high-damage vs. bad-intention low-damage), B (good-low vs. bad-low), and $\mathrm{E}$ (bad-high vs. bad-low) conformed to a Guttman scale, with the following order of difficulty from the easiest to the hardest: type B, A, and E. On the basis of these results, he proposed the following 4-stage developmental sequence in children's naughtiness judgments: (1) intentions irrelevant, (2) intentions relevant but damages more important, (3) intentions more important than damages but damages still relevant, and (4) intentions alone relevant.

Story pairs used for the Baldwins' study were similar to the story type B for the Gutkin's study regarding how the two variables, benefits and intentions, were to 
Table 1

Three story types in the judgments of kindness

\begin{tabular}{|c|c|c|c|c|c|c|}
\hline & \multicolumn{2}{|c|}{ Type-A' story pair } & \multicolumn{2}{|c|}{ 'Type-B' story pair } & \multicolumn{2}{|c|}{ 'Type-E' story pair } \\
\hline & Story 1 & Story 2 & Story 1 & Story 2 & Story 1 & Story 2 \\
\hline $\begin{array}{l}\text { Intentionality } \\
\text { Benefit }\end{array}$ & $\begin{array}{l}\text { Intentional } \\
\text { Small }\end{array}$ & $\begin{array}{l}\text { Accidental } \\
\text { Large }\end{array}$ & $\begin{array}{l}\text { Intentional } \\
\text { Large }\end{array}$ & $\begin{array}{l}\text { Accidental } \\
\text { Large }\end{array}$ & $\begin{array}{l}\text { Intentional } \\
\text { Small }\end{array}$ & $\begin{array}{l}\text { Intentional } \\
\text { Large }\end{array}$ \\
\hline
\end{tabular}

be combined; the values of benefits were held constant, while only the values of intentions were varied. This story type B seems much easier to judge on the basis of intentions. Therefore, in addition to the type B story it is necessary to assess the A and $\mathrm{E}$ story types which are regarded more difficult, in order to examine to what extent the child judges on the basis of intentions become influenced by the differential values on benefits.

The present study attempts to construct three story types on judgments of kindness which are similar to the Gutkin's (Table 1) in order to examine the following hypotheses; (a) the three different story types $\left(\mathrm{B}^{\prime}, \mathrm{A}^{\prime}\right.$, and $\left.\mathrm{E}^{\prime}\right)$ will elicit a different number of kindness judgments based on intentions, and (b) these three story types will constitute a Guttman scale. In addition, it is hypothesized that a 4-stage developmental sequence can also be applicable to the children's judgments of kindness, if the above two hypotheses were to hold.

\section{Method}

\section{Subjects}

The participants for this study consisted of 63 Japanese boys and girls: 22 kindergarteners (11 males and 11 females; Mean CA, 5: 05), 21 first graders in elementary school (11 males and 10 females; Mean CA, 7:05), and 20 third graders (10 males and 10 females; Mean CA, 9:05).

\section{Measures}

The Kindness-Judgment Interview contained three different story types $\left(\mathrm{B}^{\prime}, \mathrm{A}^{\prime}\right.$, and $E^{\prime}$ ). Each story type had two story pairs; for each story type, the protagonists in one story-pair were boys and those in another were girls.

A typical story-pair (the $\mathrm{A}^{\prime}$ story type, for example) looks like the following. (a) All three balls with which three girls were playing got caught in a tree. They could not reach them. Jiro who observed the incident jumped up to grab the balls for them. But the balls were high in the tree, and he could grab only one of them. So, the girls cannot help playing with one ball. (b) All three balls with which three girls were playing got caught in a tree again. They could not reach them. Taro who was playing with a ball near them did not know what had happened. A ball thrown by Taro happened to hit the three balls in the tree. They all dropped to the ground and the girls could get them. So, the girls were able to play with their balls happily.

\section{Procedure}

All children were interviewed individually. The experimenter read the story pairs slowly, while showing the illustrative pictures which depicted contents of the story. After making sure of the subject's understanding of the story-pair, the experimenter asked, "Who is the kinder, or are they the same?" (judgment), and then asked, "Why?" (reasoning). When the subject's responses to the question were not easy to understand, the probe was tried to clarify them. The subject's responses were all tape-recorded.

A value " 1 " was given to the response in which the intentional kindness were referred to in both judgment and reasoning. For the other response, a value " 0 " was assigned. 
Table. 2

Mcans and standard deviations for scores on kindness judgments based on intention for the three grade groups

\begin{tabular}{ccc}
\hline Grade & Mean & SD \\
\hline Kindergarten & 2.55 & 1.20 \\
First & 4.57 & 1.33 \\
Third & 5.40 & 0.80
\end{tabular}

Table 3

Means and standard deviations for scores on kindness judgments based on intention for the three story types

\begin{tabular}{ccc}
\hline Story type & Mean & $S D$ \\
\hline $\mathrm{A}^{\prime}$ & 1.46 & 0.77 \\
$\mathrm{~B}^{\prime}$ & 1.87 & 0.33 \\
$\mathrm{E}^{\prime}$ & 0.79 & 0.89
\end{tabular}

Table 4

Number of subjects showing each response pattern in $\mathrm{B}^{\prime}, \mathrm{A}^{\prime}, \mathrm{E}^{\prime}$ story types based on the scalogram analysis

$\begin{array}{cccccc} & \text { Type B' } & \text { Type A' } & \text { Type E' } & \text { No. of Subjects } & \% \\ \text { Stage 4 } & + & + & + & 21 & 33.33 \\ \text { Stage 3 } & + & + & - & 23 & 36.51 \\ \text { Stage 2 } & + & - & - & 11 & 17.46 \\ \text { Stage 1 } & - & - & - & 6 & 9.52 \\ \text { Other }^{\mathrm{k}\}} & & & & 2 & 3.18\end{array}$

Notes: Coefficient of reproducibility $=.989$

+ judgment based on intentions

- judgment based on benefits

a) signifies the deviant scale type

\section{Results}

For each grade, no sex differences in mean scores of the kindness judgments were found. Morcover, there existed no sex differences in regard to the difference in child sex that appeared in the story and the difference in sex of the subjects. Thesc results were consistent with those of Baldwin and Baldwin (1970). Therefore, the sex variable was excluded for the subsequent analysis.

\section{Age-Related Differences}

The comparisons of mean values between grade groups (Table 2) showed that the mean of the third graders was significantly higher than that of the first graders and kindergarteners $(t=2.83, d f=33, p<$ .05 , and $t=8.91, d f=37, p<.001$, respectively). Also the mean of the first graders was significantly higher than that of the kindergarteners $(t=5.11, d f=41, p<.001)$.

\section{Story Type Differences}

Results of mean comparisons between story types (Table 3) indicated that the mean of the story type $B^{\prime}$ was significantly higher than that of the story type $\mathrm{A}^{\prime}(r=$ $.47, t=4.17, d f=62, p<.001)$. Also the story type $\mathrm{A}^{\prime}$ was found to have a significantly higher mean value compared to the story type $\mathrm{E}^{\prime}(r=.60, t=6.94, d f=62, p<$ $.001)$. These results suggest that the three story types of the Kindness-Judgment should have differential difficulty levels, which conforms to a Guttman scale with the following order from the easiest to the hardest: type $B^{\prime}, A^{\prime}$, and $E^{\prime}$.

A scalogram analysis was performed on the basis of responses given to each pair. Through examining eight possible response combinations over the three story types, the highest coefficient of reproducibility was found to be .989 . Thus, the three story types under consideration was found to form an almost perfect Guttman scale. 
Table 4 shows the number of subjects who fell into each response combination under which the highest coefficient was produced. The results of this scalogram analysis suggested that development of judgments of kindness goes through four stages with progressive refinement in terms of story types considered here.

\section{An Examination of the Developmental Sequen- tiality Suggested by the Scalogram Analysis}

In order to examine the developmental sequentiality of these four stages, subjects' grade levels were identified and evaluated at each stage. Two subjects who were failed to be classified into a proper stage in the scalogram analysis were dropped from this analysis. The results of this analysis is shown in Fig. 1, indicating that the higher the grade level of the subjects, the higher the developmental stage they were likely to belong to. This results given a support to the notion that the 4stage sequence follows the order of developmental sequentiality.

\section{Discussion}

One of the most important findings of the present study was that the intentional beneficial acts were judged as kinder with increase in age. This result was consistent with one shown by the Baldwins' study (1970). Among the literature of

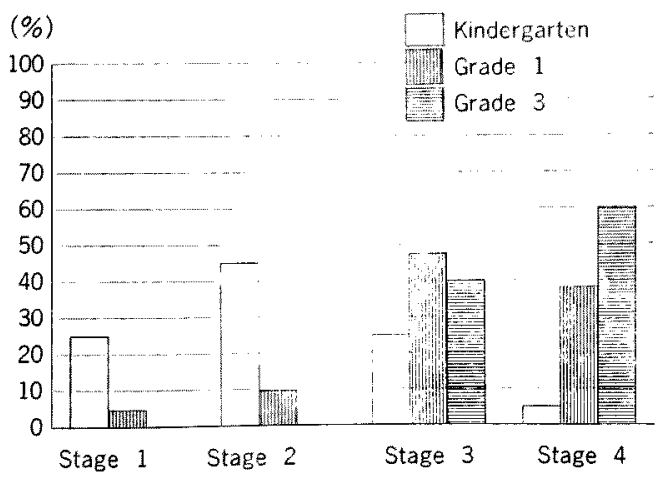

Fig. 1. Percentage of subjects in each grade classified into the four stage groups. children's naughtiness judgments (Bandura \& McDonald, 1963; Cowan, Langer, Heavenrich, \& Nathanson, 1969; Gutkin, 1972; Ninomiya, 1979; Piaget, 1932 etc.), it was generally supported that younger children focus on the consequences of behaviors while older children take intentions into account. The present study suggests that in the area of kindness judgment children change the base of their judgments by the same manner as seen in naughtiness judgment, namely changing from focusing on the consequences (amount of benefits) to on intentions as bases of judgment, with increase in age.

The second finding indicated that the kindness judgments on the basis of intentions were derived differently in accordance with the difference of three story types ( $\mathrm{A}^{\prime}, \mathrm{B}^{\prime}$, and $\mathrm{E}^{\prime}$ types). It was found that these types conformed to the requirement of a Guttman scale. This finding was consistent with the results reported by Gutkin (1972) and Ninomiya (1980, 1982) based on the study of children's naughtiness judgments. It was recognized that the story pairs used for the Baldwins' study (1970) belonged to the easiest story types for the children to judge kindness on the basis of intentions. Moreover, results of the present study suggested that development of kindness judgments goes through four stages, with showing progressive refinements in a manner quite similar to development of naughtiness judgments. The 4-stage developmental sequence can be described as following.

Stage 1. In judging kind acts, the children do not take into account intentions of the actor but only consider consequences of the act such as the amount of benefits.

Stage 2. The children believe that intentions have some relevance for assessing kindness, but do not consider intentions as more important than benefits.

Stage 3. At this stage, children believe not only intentions are relevant, but also they are more important than benefits. However, they still think that benefits are 
relevant too.

Slage 1. The children now believe benefits need not be considered in making judgnent of kind acts, but it is intentions alone that count in such judgment.

It was also suggested that this 4-stage developmental model has developmental sequentiality with a considerable clarity (Fig. 1). This finding indicated that the Baldwins" study (1970) dealt with only the first two stages specified by the 4-stage model of this study.

Further researches are needed to examine the developmental process of kindness judgments based on the other aspects, e.g. obedience, self-sacrifice, and so forth. Moreover, as Baldwin and Baldwin (1970) pointed out, it is necessary to investigate whether there is any relationship between a judgment of kindness and an actual act of kindness.

\section{References}

Baldwin, C. P., \& Baldwin, A. L. 1970 Children's judgments of kindness. Child Development, 41, 29-47.
Bandura, A., \& McDonald, F. 1963 Influence of social reinforcement and the behavior of models in shaping children's moral judgments. Journal of Alnormal and Social Psychology, 67, 274-281.

Cowan, P., Langer, J, Heavenrich, J., \& Nathanson, M. 1969 Social learning and Piaget's cognitive theory of moral development. Journal of Personality and Social Psychology, 11, 261-274.

Gutkin, D.C. 1972 'The effect of systematic story changes on intentionality in children's moral judgments. Child Development, 43, 187-195.

Heider, F. 1958 The psychology of interpersonal relalions. New York: Wiley.

Ninomiya, K. 1979 Recognition of intention and effect of modeling on children's moral judgments. Japanese Journal of Educational Psychology, 27, 1-10. (In Japanese with English summary)

Ninomiya, K. 1980 A study of children's moral judgments: An experimental test of the sequentiality of Gutkin's 4 stages. Japanese Journal of Educational Psychology, 28, 18-27. (In Japanese with English summary)

Ninomiya, K. 1982 Development of children's moral judgments: An examination of the developmental synchronism in Gutkin's 4 stages. Japanese Journal of Educational Psychology, 30, 282286. (In Japanese)

Piaget, J. 1932 The moral judgment of the child. London: Routledge \& Kegan Paul.

(Received July 22, 1986; accepted Sept. 20, 1986) 